REVISTA DE ESTUDOS EM ARTES CÊNICAS

E-ISSN 2358.6958

\title{
Escritos da pandemia: \\ Três breves textos de Anne Bogart sobre Covid-19 e o futuro da direção teatral
}

Anne Bogart

Tradução: Fabiano Lodi

\section{Para citar este artigo:}

Bogart, Anne. Escritos da pandemia: Três breves textos de Anne Bogart sobre Covid-19 e o futuro da direção teatral. Trad. Fabiano Lodi. Urdimento - Revista de Estudos em Artes Cênicas, Florianópolis, v. 3, n. 42, p. 1-20, dez. 2021.

doi DOI: http:/dx.doi.org/10.5965/1414573103422021e0701 


\title{
Escritos da pandemia: três breves textos de Anne Bogart sobre Covid-
} 19 e o futuro da direção teatral ${ }^{1}$

Anne Bogart ${ }^{2}$

Tradução: Fabiano Lodi

\begin{abstract}
Resumo
Este trabalho reúne três breves textos escritos pela diretora teatral estadunidense Anne Bogart traduzidos pelo diretor teatral e pesquisador brasileiro Fabiano Lodi. Tais textos dizem respeito aos impactos causados pelo fechamento dos teatros e completa paralisação das atividades artísticas devido à pandemia mundial de Covid19. A autora propõe reflexões sobre os diferentes desafios enfrentados por artistas e público desde que as regras sanitárias para conter o avanço do Coronavírus se intensificaram, a partir de março de 2020. Com isso, Bogart revisita questões éticas, culturais e políticas do passado histórico para imaginar e propor possibilidades de um futuro onde o teatro como a arte do encontro seja novamente possível.
\end{abstract}

Palavras-Chave: Direção Teatral. Covid-19. Processos Criativos.

\section{Writings on the Pandemic: Three short essays by Anne Bogart about Covid-19 and the Directing's future}

\begin{abstract}
This paper is a collection of short essays written by the American theatre director Anne Bogart and translated into Portuguese by the Brazilian theatre director and researcher Fabiano Lodi. Each one of them is about the impacts of locking down the Theatres and the complete stopping for artistic and cultural activities because of the worldwide Coronavirus pandemic, since 2020 March. Thus, Bogart proposes a review of cultural, political and ethical issues from the historical past to imagine a future in which theatre as an art of encounter will be possible again.
\end{abstract}

Keywords: Directing. Covid-19. Creative Processes.

\footnotetext{
${ }^{1}$ Revisão ortográfica e gramatical do artigo realizada por Liliana Junqueira - Graduada em Letras PortuguêsInglês pela Universidade Mackenzie. Formada pela Escola de Arte Dramática da Universidade de São Paulo (EAD/ECA/USP). Atua como professora de teatro, tradutora e revisora de textos. Atriz e arte-educadora brasileira.
}

2 Diretora teatral estadunidense, professora e coordenadora do MFA Directing Program da Universidade da Columbia, nos Estados Unidos. Seu amplo reconhecimento internacional se deu especialmente após a criação da SITI Company, companhia teatral que fundou em 1992 em parceria com o diretor teatral japonês Tadashi Suzuki, e que sustenta um treinamento artístico em que se combinam a técnica dos Viewpoints e o Método Suzuki.

${ }^{3}$ Mestre em Teatro pelo Instituto de Artes (IA) da Universidade Estadual Paulista "Júlio de Mesquita Filho" (UNESP - 2015). Licenciado em Artes Cênicas pelo Centro de Artes (CEART) da Universidade do Estado de Santa Catarina (UDESC - 2009). Desde 2005, dedica-se ao estudo de procedimentos práticos em direção teatral, envolvendo os Métodos Suzuki e Viewpoints. Diretor teatral brasileiro, pesquisador e professor. fabiano.lodi@gmail.com

(6) http://lattes.cnpq.br/1564492901035838

https://orcid.org/0000-0003-3882-7022 


\section{Escritos pandémicos: Tres textos cortos de Anne Bogart sobre Covid- 19 y el futuro de la dirección escénica}

\section{Resumen}

Este trabajo se constituye por tres textos cortos escritos por la directora teatral estadounidense Anne Bogart traducidos para el portugués por el director brasileño y investigador teatral Fabiano Lodi. Estos textos se refieren a los impactos provocados por el cierre de teatros y la paralización total de las actividades artísticas debido a la pandemia mundial de Covid-19. La autora propone reflexiones sobre diferentes desafíos que artistas y el público enfrentan desde que se han intensificado las normativas sanitarias para contener el avance del Coronavirus a partir de marzo de 2020. Así pues, Bogart revisa cuestiones éticas, culturales y políticas del pasado histórico para imaginar y proponer un futuro de posibilidades en el que el teatro como arte del encuentro vuelva a ser posible.

Palabras clave: Dirección Escénica. Covid-19. Procesos Creativos. 


\section{Introdução}

Este trabalho reúne três breves textos escritos pela diretora teatral estadunidense Anne Bogart, por mim traduzidos e revisados por Liliana Junqueira, os quais levantam diferentes abordagens e reflexões relacionadas à arte da direção teatral. Além disso, cabe ressaltar que foram escritos durante o período de isolamento social que parte expressiva do mundo experimentou como medida para mitigar o avanço do Coronavírus, a partir de março de 2020. Ao destacar o contexto de pandemia mundial como um paradigma capaz de transformar profundamente os parâmetros sobre o fazer artístico, Bogart revisita acontecimentos históricos de proporções semelhantes para imaginar o futuro do teatro e da direção teatral num mundo pós-pandemia.

Os textos aqui reunidos foram publicados entre maio de 2020 e junho de 2021 no blog que Bogart mantém desde $2008^{5}$. A escrita é uma das atividades pelas quais Bogart se destaca desde 2001, quando lançou A Director Prepares pela editora TCG, de Nova York. Desde então, publicou mais 04 livros $^{6}$, totalizando 05 obras de sua autoria, além da participação como colaboradora e organizadora em outras tantas publicações. Dois de seus livros já foram editados em português no Brasil: A Preparação do Diretor pela Editora WMF Martins Fontes em 2011, e O Livro dos Viewpoints pela Editora Perspectiva em 2017 - este último, cujo projeto de tradução surgiu no grupo de pesquisas O Corpomente em Cena, coordenado pela pesquisadora e professora Dra. Sandra Meyer entre 2006 e 2012 na UDESC e do qual fui integrante, colaborando diretamente no processo de tradução.

Bogart utiliza seu blog como um espaço para compartilhar textos ensaísticos, articulando aspectos de sua vida pessoal e carreira artística aos temas que se

\footnotetext{
${ }^{4}$ Blog de Anne Bogart: https://siti.org/author/anne-bogart - no ar desde janeiro de 2012.

${ }^{5}$ O primeiro blog de Anne Bogart, atualmente desativado e inacessível, ficou no ar entre novembro de 2008 e janeiro de 2012 sob o seguinte endereço: https://siti.groupsite.com/blog

${ }^{6}$ The Viewpoints Book (2005); And Then You Act (2007); What's the Story (2014); The Art of Resonance (2021).
} 
propõe a desenvolver. Na pesquisa que realizei durante o mestrado ${ }^{7}$, analisei as características das publicações do blog e dos livros de Bogart. Frequentemente, seus textos são lançados primeiramente no blog e, alguns deles recebem um tratamento aprimorado para compor capítulos inteiros ou conteúdos parciais de seus livros impressos. Esta prática indica o caráter processual das reflexões desenvolvidas por Bogart e sua fidelidade a algumas características de escrita, observáveis tanto em seus livros quanto no blog e, portanto, nos textos aqui traduzidos. É possível notar, por exemplo: uma redação cuidadosamente preparada para facilitar o entendimento de uma ampla gama de leitoras e leitores, gerando o mínimo de obstáculos linguísticos; o uso da primeira pessoa e do lugar de fala; relação imbricada entre relatos pessoais e temáticas sociais; ênfase nas reflexões sobre a arte da direção teatral, especialmente quando exercida por mulheres; uso de vocabulário coloquial e cotidiano. Certamente, a experiência de leitura dos textos de autoria de Bogart pode revelar outras combinações e acionar tantas percepções para somarmos a estas aqui já destacadas.

Os textos estão dispostos na seguinte sequência: $A$ ilusão do controle, publicado em 11 de maio de 2020; Onde eu paro e onde você começa?, publicado em 10 de maio de 2021; A arte da ressonância, publicado em 14 de junho de 2021. Em A ilusão do controle, Bogart recorre a diferentes áreas do conhecimento para analisar, sob o contexto de incertezas causadas pela pandemia, nossas relações com o desejo de controle e o quanto essa busca altera a percepção dos sentidos, gerando ansiedade e desconexão com a realidade. Em Onde eu paro e onde você começa? Bogart traça uma revisão histórica sobre um expressivo legado de práticas relacionadas à direção teatral, destacando a urgência por mudanças estruturais já em movimento antes da pandemia, propondo imagens para um futuro em que não se repitam atitudes perversas, excludentes e autoritárias que marcaram o passado. Por fim, em $A$ arte da ressonância Bogart comenta sobre o processo de escrita do livro homônimo de sua autoria, lançado em setembro de 2021 e que teve parte significativa de seu conteúdo desenvolvido no contexto do isolamento social de 2020.

7 Fabiano Lodi. Direção teatral na perspectiva de Anne Bogart. 2015. Dissertação (Mestrado em Artes - Teatro) - Instituto de Artes (IA) - Universidade Estadual Paulista "Júlio de Mesquita Filho" (UNESP), São Paulo, 2015.

Disponível em: https://repositorio.unesp.br/handle/11449/136698. Acesso em: 09 ago. 2021. 
Por mais que seja possível observar um número crescente de reflexões teóricas, arranjos metodológicos e outros aspectos relacionados à direção teatral, este repertório ainda é escasso se comparado, por exemplo, às literaturas sobre história do teatro ocidental e a arte da atuação. Essa escassez de referências se estreita ainda mais quando notamos que a autoria de grande parte dos estudos publicados sobre direção (ainda) é assinada por homens, bem como a maioria dos artistas consagrados no exercício deste ofício.

Neste sentido, a trajetória de Anne Bogart se destaca com expressiva relevância, rompendo a previsibilidade e ampliando espaços para que a diversidade de referências e perspectivas ecoe. Para nós, que vivemos no Brasil e na América Latina, pode ser necessário um processo de adaptação e aproximação às nossas realidades frente ao que Bogart articula mediante o contexto dos Estados Unidos. Ainda assim, acredito na ampla dimensão e impacto de suas proposições notadas nos textos aqui traduzidos, bem como no conjunto de sua obra.

Com essa publicação, espero colaborar neste processo histórico de efervescentes contribuições sobre a direção teatral. Que possamos ver mais e mais diretoras - e demais pessoas dissidentes de gênero, etnia e outras tantas invisibilidades sociais e culturais - reconhecidas, respeitadas na sua condição inerente, com voz ativa na proposição das pautas, no apontamento das urgências e transformações que precisam ser colocadas em prática. E que, oportunamente e em segurança sanitária, seja possível reeditarmos momentos de encontros especiais mediados pela produção de arte, fazendo valer os esforços para que as almejadas transformações possam emergir. Será uma ocasião propícia para saudar a memória de tantas pessoas queridas e admiráveis vencidas pela pandemia, oferecendo o nosso melhor para que um mundo de oportunidades igualitárias seja uma realidade possível.

Finalizo esta introdução destacando a participação efetiva de Bogart na escolha destes textos aqui publicados, bem como a liberdade e a confiança que uma vez mais me conferiu para encarar este desafio: encontrar as mais adequadas palavras e expressões que elucidem seu notório saber sobre o teatro e a direção teatral, seu estilo de escrita, sua posição frente aos diversos temas que the 
interessam, sua genuína personalidade inquieta e investigativa. Eis alguns atributos que me inspiram e me movem nesta jornada, agora compartilhada com todas e todos vocês. Boa leitura!

\title{
Artigo 01: A ilusão do controle
}

\author{
Mas um homem cheio de orgulho \\ veste-se de um pouco de autoridade \\ Ignorando aquilo de que mais tem certeza \\ Com sua essência fraca de animal irritado \\ E truques fantásticos diante dos céus \\ Faz os anjos chorarem. \\ (William Shakespeare)
}

Normalmente, quanto mais incerta eu estou, mais eu anseio controle. Quero me sentir no controle e exercê-lo porque me sinto mais segura quando acredito que posso controlar as coisas. Mas neste atual estado de isolamento social em casa, posso não estar experimentando sozinha a sensação avassaladora de que não controlo quase nada. Diante de tanta imprevisibilidade, tenho a oportunidade de refletir sobre o controle de novas maneiras.

Aos treze anos de idade fui sexualmente abusada por um homem, no alto de um trator, nas colinas rurais de Rhode Island. O choque do encontro com suas enormes partes viris é algo de que não consegui me livrar por muitos anos. Apesar do terror e do trauma físico daquele encontro, nunca falei com meus pais sobre isso. De fato, por muitos anos eu não contei nada a ninguém. Temia que, se confessasse, não teria mais permissão para andar livremente pelo campo. Mas me senti culpada, confusa e assombrada pelo incidente. E houve consequências e uma mudança em meu comportamento. Passei a ter medo de altura e de lugares íngremes. Passei a comer com uma intensidade nova para engolir meus medos e, talvez, como os psicólogos sugerem, para me tornar menos atraente para os homens. Desde então, venho enfrentando problemas de sobrepeso. E então, ao longo dos anos, para perder peso, para ter algum tipo de controle sobre minha ansiedade, fiz dietas rígidas. Evidentemente, eu estava tentando assumir o controle 
de algo em meio a um mundo que parecia ser incontrolável, perigoso e imprevisível.

Aos quinze anos, me apaixonei pelo teatro. Não sei o quanto da escolha por me tornar uma diretora se deu pela necessidade de controlar as condições. Certamente, essa profissão sempre teve muito a ver com questões de controle. Como diretora, sinto que podia exercer algum controle sobre a atmosfera dos ensaios, bem como sobre os padrões éticos e o nível de escuta e respeito, solicitar uma dedicação específica da qualidade de presença da equipe, demitir pessoas que não estivessem à altura dos desafios propostos. Minhas próprias ambições quanto à carreira pareciam estar ligadas ao medo de cair, se debater ou se afogar.

Minha esposa Rena frequentemente me pede para parar de ser diretora em casa. E ela está certa. Tenho sempre de me atentar que as tentativas de controlar os eventos da minha vida me impediram de vivê-la plenamente, desfrutando dos seus prazeres. Há muitos anos, meus estudos de T'ai Chi Chuan e Aikidô equilibraram minha necessidade de controle. Ambas são práticas de "artes marciais internas", fundadas sobre princípios filosóficos consistentes relacionados a ceder completamente a um ataque e, em seguida, usar a energia do ataque para derrotar o atacante. Tanto o $T^{\prime}$ ai Chi Chuan quanto o Aikidô enfatizam a harmonia entre o corpo, a mente e o ambiente ao redor. Ambas envolvem movimentos contínuos e harmônicos. O Aikidô, em particular, me colocou frente a frente com o medo de cair, já que grande parte das práticas consiste em fazer rolamentos e quedas.

T'ai Chi Chuan foi fundado sobre princípios Taoístas. Explicando de modo bem simples, a filosofia Taoísta nos ensina como viver e nos mover em harmonia com as forças da natureza. Imagine um peixe que nada num mar agitado. Ele não tem a ilusão de que controla o mar ou os outros peixes. Nem mesmo seu destino tenta controlar. O peixe simplesmente nada. O estudo do Taoísmo e do T’ai Chi Chuan me incentivou a crer nos meus valores e nadar na corrente das circunstâncias que se apresentam a cada instante. 
Uma mestra permite que as coisas aconteçam Ela $^{9}$ molda os eventos conforme surgem

Ela sai do caminho e deixa o Tao falar por si mesmo.

A ilusão do controle é uma tendência de pessoas que superestimam suas habilidades de controlar e influenciar os eventos. Nós, humanos, temos uma forte inclinação para manipular o ambiente ao nosso redor, já que as situações que parecem ideais são aquelas em que nos sentimos no completo domínio dos resultados. Quando fazemos julgamentos e tomamos decisões sobre o mundo ao nosso redor, queremos sentir que somos objetivos, lógicos, capazes de digerir e avaliar as informações disponíveis. Quando estamos no controle, sentimos que brilhamos aos olhos das outras pessoas. Mas a verdade é que esses momentos são menos comuns do que imaginamos. Em termos cognitivos, trata-se de uma falha que ocorre no processamento e interpretação das informações, que distorcem nossos pensamentos e percepções.

A ilusão do controle é um viés cognitivo que me leva a supor que tenho controle sobre os resultados. E, de fato, isso raramente acontece. Alguns destes vieses estão relacionados à memória, e outros a problemas de atenção porque, na verdade, a atenção é um recurso extremamente limitado. Sutis predisposições podem se instalar e influenciar a maneira como vejo e penso o mundo. Meu cérebro tenta naturalmente simplificar as informações recebidas para que eu possa tomar decisões rapidamente. Minha pressa pode produzir erros de cálculo. Essas falhas no pensamento podem, então, afetar radicalmente meus julgamentos e as decisões que eu tomo.

Os seres humanos, bem como todas as criaturas vivas, buscam padrões a fim de dar sentido ao mundo. Humanos podem ser os únicos a atribuir significados simbólicos a tais padrões, muitas vezes com amplas nuances ou poderoso conteúdo emocional. E uma vez percebidos, tecemos narrativas para explicar os padrões ilusórios. De acordo com estudos recentes, a sensação de falta de

9 Não há distinção de gênero nos escritos Taoístas de Lao Tzu em língua chinesa. No entanto, usa-se frequentemente o feminino nas traduções para idiomas em que existe essa distinção, já que o ensinamento central do Taoísmo considera o princípio feminino como uma manifestação do divino. (NT) 
controle aumenta essa tendência pelo reconhecimento de padrões, intensificando a busca para se obter algum controle. No entanto, este padrão de reconhecimento hiperativo nos leva a falsas percepções e a uma sensação de controle ilusória.

Ao longo da história, os seres humanos desenvolveram rituais e cerimônias para influenciar os eventos e controlar o ambiente. Tais ritos incluem danças e cerimônias de sacrifício para influenciar no clima, melhorar a colheita, garantir a vitória em uma batalha, aplacar os inimigos ou afastar os maus espíritos. Atualmente sabemos que o clima e o nosso ambiente não são coisas que conseguimos controlar facilmente por meio de ritos cerimoniais. Entendemos que os humanos têm muito menos controle sobre os eventos do que se imaginava.

Sentir falta de controle geralmente nos deixa ansiosos, e nos leva a adotar rituais supersticiosos que prometem aliviar essa ansiedade. Amplamente arraigada nas religiões, manifestações populares e mitologias, a superstição é uma estratégia consciente para controlar o ambiente. Há muito tempo, as superstições e pensamentos mágicos ${ }^{10}$ - a crença de que uma ação, símbolo ou evento pode causar resultado sem que haja conexão lógica - têm ajudado a humanidade a dar sentido a um mundo caótico. Isso nos dá uma ilusão de controle na crença de que podemos atrair sorte ou azar. E é um dos motivos pelos quais esportistas profissionais e apostadores em jogos de azar ${ }^{11}$ tendem a ser supersticiosos. Eles correm grandes riscos em resultados sobre os quais têm controle incompleto, ou mesmo, nenhum controle. Os apostadores tendem a lançar os dados com mais força quando querem um número mais alto e mais suave quando querem um número baixo. Nas máquinas de caça-níqueis, as pessoas tentarão controlar o resultado pela maneira com a qual puxam a alavanca. Nós batemos na madeira para ter sorte. Os TOC's são tentativas de controlar a vida. De fato, todas estas ações não têm impacto real sobre os resultados, embora as pessoas gostem de pensar que são racionais e que refletem sobre as coisas antes de agir.

Talvez um forte viés cognitivo tenha surgido durante o século XVIII, num período conhecido como Iluminismo. Diversos filósofos e intelectuais europeus

10 Termo frequentemente empregado na ciência cognitiva (NT).

${ }^{11}$ No original: high-stakes gamblers. 
propuseram que a ciência e a razão poderiam superar o mistério, o caos e nossa conexão com os grandes ciclos da natureza. O Iluminismo questionou a autoridade tradicional e abraçou a ideia de que a humanidade poderia ser melhorada por meio de mudanças racionais. Este período histórico também testemunhou um interesse crescente na compreensão e uso da ciência, em vez da religião, para explicar os fenômenos naturais. Com o pretexto do humanismo, no sentido de "maximizar a prosperidade humana", nossa espécie se colocou no centro do universo, propondo que pensamento e análise - capacidades mentais de racionalizar sobre os problemas - poderiam liderar a reorientação da política, filosofia e ciência. Essa mudança nos incutiu, até hoje, a sensação de que merecemos certezas sobre o futuro.

Mas, certamente, a incerteza é inerente à condição humana. Por mais que tentemos nos cercar com o máximo de garantias possíveis, habitamos um mar de incertezas. E o lluminismo pode ter sido um grande impulso na tentativa de dominar o mundo através da produtividade, revoluções políticas e desenvolvimento tecnológico, científico e industrial.

E agora, em 2020, esse ímpeto de avanço, esse progresso aparentemente desenfreado, foi inesperadamente interrompido. Mas esta não foi a primeira vez que o botão de pausar foi pressionado. Fomos pegos de surpresa com a queda da União Soviética em 1989 e o colapso do World Trade Center em 2001. Estes eventos aconteceram de forma inesperada, embora em retrospecto talvez fossem, assim como o Coronavírus, inevitáveis. Mas nós, e nem mesmo os governos que sabiam das ameaças, estávamos preparados. Agora, na pressa de controlar o vírus, vemos o quão pouco, de fato, o controlamos.

Neste momento, a verdadeira natureza da incerteza está presente e palpável. O índice de desemprego causado pelo Coronavírus aumenta diariamente. A incerteza sobre quando será seguro nos reunirmos com a família, amigos e colegas de trabalho é uma realidade atual. A incapacidade de poder confortar aqueles que estão nos hospitais parece insustentável. Não posso parar de pensar no sofrimento e solidão das pessoas que estão morrendo e no sofrimento daqueles que as amam e que estão proibidos de expressar sua ternura e amor, isso sem falar na falta dos ritos essenciais de luto elementares em qualquer civilização. 
Mas, talvez, à luz dessa pandemia, possamos mudar nossas expectativas. A perspectiva de um futuro seguro sempre foi uma ilusão, de qualquer maneira. Atualmente, sabemos muito pouco sobre o Coronavírus, suas origens e real periculosidade. Estamos diante de uma enorme imprevisibilidade e, quem sabe, de uma convulsão social iminente com consequências econômicas radicais. Neste novo cenário, podemos refletir sobre a incerteza e reavaliar nossas suposições sobre o que realmente importa.

Em relação ao futuro, nós definitivamente seremos convocados a inovar, a ativar nossa imaginação de diferentes formas e a agir com empatia e dignidade. Havemos de inventar uma nova realidade sob circunstâncias desconhecidas. Essas inovações, e as ações que deverão acontecer para chegarmos a elas, exigirão razão, engenhosidade, confiança e coragem, além de uma abertura a novos paradigmas científicos, econômicos e políticos.

Historicamente, as pandemias forçam os seres humanos a romper com
o passado e imaginar um mundo novo. Desta vez não é diferente. Trata-
se de um portal, uma passagem entre este mundo e o próximo. Podemos
escolher caminhar por ele arrastando as carcaças de nossos
preconceitos e ódios, nossos bancos de dados e ideias mortas, nossos
rios e céus poluídos. Ou podemos caminhar com leveza, pouca bagagem,
prontos para imaginar outro mundo. E lutar por ele. (Arundhati Roy)

Ao longo dos últimos dois meses, Rena e eu temos vivido o isolamento social em Londres com Mabel, nossa cachorrinha Golden Retriever que está crescendo rapidamente. Caminhamos todas as manhãs no Kensington Garden, que é perto de nossa casa. Os britânicos têm permissão para entrar nos parques uma vez ao dia para fazer exercícios ou andar com seus cãezinhos. Ficamos amigas de uma família que tem um pequeno Labrador chamado Leo. Desde então, nossos horários de visita ao parque coincidem. Mabel e Leo se adoram e não nos cansamos de assisti-los rolarem um sobre o outro com gosto e alegria. Estes encontros diários têm se tornado significativos em nossas vidas durante este período de pandemia. Certo dia da semana passada, Rena, Mabel e eu chegamos ao parque e não encontramos o Leo e sua família, que também não atendiam às nossas ligações. Ficamos imediatamente preocupadas em relação ao estado de 
saúde dos nossos novos amigos. Sem perceber, tínhamos ficado envolvidas demais nos novos significados de nossas relações.

Uma característica fundamental da inteligência humana é criar significados, atribuir sentido às coisas que percebemos ao nosso redor e às relações com outras pessoas. Damos sentido ao mundo. O significado da amizade é importante. Novos sentidos que criamos a partir da atual mudança de paradigma serão importantes. O que podemos controlar acaba sendo nossa própria atitude em relação às circunstâncias e, até certo ponto, nossas posturas físicas, mentais e emocionais. Podemos criar e celebrar novos significados a partir das condições que se apresentam.

\section{Artigo 02: Onde eu paro e onde você começa?}

Quando tentamos escolher qualquer coisa por si só, descobrimos que está atrelada a tudo que existe no universo.

(John Muir)

O DNA do teatro é a conexão humana. Tanto a criação quanto a apreciação de uma performance exigem cooperação e colaboração, não apenas entre o público e os atores, mas também com toda a equipe criativa que faz parte da montagem. Algumas formas de teatro requerem mais coautoria do que outras. Por exemplo, no método autoral ${ }^{12}$, o diretor exerce sua singularidade e alto nível de controle sobre a produção, envolvendo menos o pensamento lateral ${ }^{13}$ do que,

\footnotetext{
12 No original: auteur theater. Mesmo no idioma inglês, usa-se comumente este termo em francês (auteur) para se referir à prática de diretores teatrais que determinam os aspectos da encenação segundo suas preferências estéticas, conferindo um estilo característico à obra por meio da combinação singular de diferentes elementos cênicos, como uma assinatura que o identifica. Neste processo, o diretor ocupa uma posição destacada na hierarquia artística, liderando a equipe criativa para que executem as proposições que respeitem seu ponto de vista e conceito artístico. (NT)

${ }^{13}$ Conceito desenvolvido pelo escritor Edward de Bono (1933-2021), articulado por Bogart em seus processos criativos como diretora, especialmente nas práticas de Composição. Para mais informações, consultar: Anne Bogart; Tina landau. O Livro dos Viewpoints - um guia prático para Viewpoints e Composição. Tradução: Sandra Meyer. São Paulo: Editora Perspectiva, 2017.
} 
digamos, em um processo colaborativo ${ }^{14}$, que exige grande potencial de cooperação entre os integrantes do grupo de artistas.

Quando eu dirijo uma ópera, sei muito bem quanta preparação é necessária para que se iniciem os ensaios. Devo chegar ao primeiro encontro com um plano de trabalho cuidadosamente elaborado para cada momento de cena. Onde e em qual exato momento da música os cantores entram? Seguem a qual sequência de ações? Onde fica o coro e o que eles fazem, exatamente, a cada momento? Para dirigir uma ópera, devo me inclinar para a parte mais "autora” do meu cérebro. ${ }^{15}$

Cada processo criativo evoca diferentes funções mentais e diversas formas de pensamento e colaboração com outras pessoas. Como humanos, temos a sorte de sermos dotados da capacidade de trabalharmos juntos lindamente e cooperarmos no processo de reflexão, invenção e inovação. Foi esta nossa amizade, sociabilidade, habilidade e inclinação para trabalharmos juntos e de copiarmos um ao outro que levou o Homo sapiens a prosperar sobre muitas outras espécies de Homo erectus. No livro Humankind, o historiador Rutger Bregman mostrou como os Homo sapiens prosperaram no planeta, ao contrário dos Neandertais, mesmo com sua força física e grande cérebro. Os Neandertais eram muito inovadores e haviam desenvolvido ferramentas, produzido fogo e cozinhado seus alimentos, mas no fim foram os Homo sapiens que sobreviveram. Embora fossem inteligentes, os Neandertais não eram seres sociais e não costumavam trabalhar em equipe. Por outro lado, os Homo sapiens se beneficiaram de suas habilidades cooperativas. "Ao que parece, os seres humanos são máquinas de aprendizagem ultrassociais". Bregman escreve, "Nascemos para aprender, criar vínculos e brincar".

No processo colaborativo, em oposição a uma abordagem mais verticalizada, todo o grupo de artistas é convocado a pensar junto e cooperar para atingir algo além da mera interpretação de uma peça previamente escrita. Muito do processo

\footnotetext{
${ }^{14}$ No original: devised work. Embora existam diversas definições e arranjos que possam ser assim nomeados, optamos por traduzir este termo como "processo colaborativo" no contexto trazido pela autora por se diferenciar de outros formatos de criação - que não são colaborativos - por ela cotejados. (NT)

${ }^{15}$ Neste parágrafo, Bogart exemplifica o uso de uma abordagem vertical para a direção teatral utilizando o termo auteur (em que o diretor é soberano enquanto "autor" da encenação) como uma qualidade do ofício de direção teatral a que se pode recorrer oportunamente.
} 
colaborativo resulta da química existente entre os cocriadores. Esta prática requer pensamento lateral, que é uma maneira de resolver problemas usando uma abordagem indireta e criativa por meio de um raciocínio que não é imediatamente óbvio. E então o público chega à cena e, como em todas as melhores experiências teatrais, é o cocriador final.

Há um poder na linguagem, no pensamento e na fala que transforma o sujeito e o mundo. Como é possível que um livro, um poema, uma conversa ou um pensamento faça isso? Adentramos no livro, poema, conversa, ou linha de raciocínio até o fim e, quando saímos, todas as coisas parecem completamente diferentes. De fato, em tais experiências, mal podemos lembrar quem éramos e como o mundo parecia.

(Levi Bryant)

No dia 11 de março de 2020 eu viajei para Londres, partindo de Nova York com a expectativa de permanecer uma semana por lá. Continuo em Londres um ano e dois meses depois. Todas as coisas passaram a acontecer online. Quase tudo pelo Zoom. Minhas aulas de Direção Teatral na Universidade de Columbia se tornaram aulas virtuais. Decidi então que, no segundo semestre de 2020, eu ofereceria aos estudantes de Pós-Graduação um módulo de análise da história da direção teatral e da direção para ópera. Num primeiro momento, considerei fazer uma abordagem cronológica. Mas parecia algo pedante e um pouco problemático.

Em termos gerais, a história da direção teatral é ensinada tradicionalmente começando pelo século XIX com o Duque de Saxe-Meiningen, seguido por Max Reinhardt, Stanislavski, Erwin Piscator, Bertolt Brecht e assim por diante. Percebi que esta abordagem não era apenas eurocêntrica, mas também um pouco arcaica. O que fez sentido para mim foi pensar sobre como os diretores contemporâneos dispõem de um repleto instrumental que foi acumulado ao longo dos anos graças às inovações radicais de tantos artistas ao redor do mundo. Nós que trabalhamos com direção hoje em dia somos os beneficiários destes avanços, e podemos selecionar as técnicas e ferramentas apropriadas para qualquer projeto em que estejamos envolvidos, baseadas nas criações de nossos antecessores.

Os movimentos mais radicais nas artes e no teatro surgiram frequentemente durante momentos de instabilidade política e de transformações culturais. Em vários momentos da história, os atos de resistência artística ao status quo 
eclodiram no universo das artes e exerceram, por sua vez, um impacto significativo não apenas nos sistemas políticos e culturais, mas também sobre como nossas performances se relacionam com o mundo. Gosto de pensar nessas explosões sociais e artísticas como big bangs que, consequentemente, engajam diferentes movimentos artísticos entre si. Nestes contextos explosivos, os artistas foram forçados a desenvolver novos formatos e pensar em outros caminhos para o teatro e a ópera. Assim, um amplo conjunto de abordagens foi gradualmente sendo acumulado na caixa de ferramentas dos diretores.

Nas minhas aulas, começo desenvolvendo uma série de palestras sobre a arte da direção teatral. Enfatizo nove momentos marcantes do teatro que resultaram em nove recursos, cada qual fomentando respostas à insatisfação com a forma como as coisas eram feitas até então. Tais insatisfações geralmente se situavam no contexto político ou social da época. Faço a abordagem sobre estas nove explosões: Teatro de Grupo, Teatro Total, Dança-Teatro, Processos Colaborativos, Artes Visuais, Diretor como Autor, Teatro Político, Teatro em Espaços Não-Convencionais e Tecnologia. E então, ao abrir essas caixas de ferramentas, os diretores podem encontrar um leque de materiais desenvolvidos por diferentes artistas através do tempo. O ethos pós-moderno nos incentiva a selecioná-los, misturá-los e combiná-los livremente. Posso transitar de uma abordagem autoral para uma prática de teatro de grupo, e depois dança-teatro e assim por diante.

E agora, enquanto tentamos sair da pandemia, erguendo nossas cabeças dos escombros, botando a cara no sol, vemos os sinais de uma paisagem alterada. Com preocupação e responsabilidades crescentes sobre a generalizada desigualdade racial, ambientes de trabalho abusivos e racismo estrutural que têm sido problemas de longo prazo, somos convocados a mudar nossos hábitos pessoais e institucionais enquanto forjamos métodos totalmente novos para fazer teatro e outros encontros com o público.

Algumas coisas já estavam se transformando bem antes da pandemia. O controle hegemônico do homem branco está desmoronando. Um bom exemplo disso se observa no universo da música. Muitas orquestras importantes têm se recusado a seguir a tradição de contratar maestros autocráticos e agressores. No 
século XX, o comportamento arrogante era muito comum em maestros como Arturo Toscanini, Herbert von Karajan e George Solti e, mais recentemente, Daniel Barenboim. Atualmente, há uma crescente antipatia por demonstrações de egoísmo e poder por parte dos maestros. "Hoje em dia, a relação entre o maestro e os músicos é mais informal e amistosa - e menos reverencial”, disse Mark Elder, maestro da Hallé Orchestra"16. "Isso não mudou a maneira como se faz música, mas exige que os maestros mostrem respeito". Comportamentos arrogantes e egocêntricos de uma estrela não colam mais e não criam necessariamente as condições para uma música melhor.

Tradicionalmente, o diretor teatral é responsável pela peça, assim como o maestro pela partitura. É imperativo recorrer a um círculo amplo de comunidades, atores, diretores, técnicos e de metodologias conforme as condições se alteram. Nossa caixa de ferramentas já é extensa, mas alguns instrumentos mais novos são necessários para avançar com sucesso em direção ao próximo paradigma.

\section{Artigo 03: A arte da ressonância}

Em setembro de 2021, meu novo livro The Art of Resonance será publicado pela editora Methuen/Bloomsbury ${ }^{17}$. E em maio, estive em estúdio por diversas vezes para gravar a versão em áudio do livro para o site Digital Theatre Plus (DT+ $)^{18}$, uma plataforma online voltada para educadores envolvidos com arte e teatro. A gravação será lançada simultaneamente com o livro e estou muito entusiasmada em compartilhar tanto o livro quanto a versão em áudio com vocês. ${ }^{19}$

Escrevi a maior parte do The Art of Resonance durante o isolamento social na Inglaterra, em Londres. Algumas vezes me senti estranha ao escrever sobre

${ }^{16}$ Orquestra sinfônica da cidade de Manchester, na Inglaterra.

\footnotetext{
17 A editora britânica Bloomsbury tem sede em Londres e conta com publicações em diversas áreas do conhecimento e estilos literários. O selo Methuen Drama reúne um amplo catálogo sobre teatro, dramaturgia e estudos relacionados às artes performáticas. E, agora, inclui o referido lançamento escrito por Anne Bogart. (NT)

${ }^{18}$ Para mais informações: https://www.digitaltheatreplus.com/practitioner/anne-bogart .

${ }^{19} \mathrm{O}$ livro impresso e o audiobook de The Art of Resonance foram lançados no dia 23 de setembro de 2021, ambos em idioma inglês. (NT)
} 
ressonância em um período tão trágico e aprisionador. Minha preocupação era de que o tema da ressonância soasse irrelevante ou alheio à agitação turbulenta dos acontecimentos recentes, da pandemia e das questões urgentes que vinham à tona diariamente e adquiriam um expressivo significado no mundo.

E entendi também que a pandemia e o isolamento social, bem como a iminência de crises políticas e sociais, ofereceram oportunidade única para reexaminar os princípios básicos do fazer teatral. A quarentena nos desacelerou, e nos possibilitou questionar algumas premissas do teatro tais como: o que estamos fazendo? Como estamos fazendo e por quê? Quais ideias inspiram nossas ações? Sobre quais valores estamos construindo o futuro? Como adaptálos? Como voltar a fazer teatro de forma inclusiva e produtiva, aproveitando-se de algo que o teatro faz de melhor ao abordar questões e circunstâncias do nosso tempo?

Nos últimos anos, começou a me ocorrer que a ressonância pode ser um dos componentes mais fundamentais do teatro. Talvez o sucesso de uma produção possa ser medido pela magnitude e qualidade da ressonância ativada pela experiência. A ressonância acontece entre os atores, entre atores e o público e inclui a reverberação contagiante das ideias e do momento presente, através do texto, movimento, musicalidade, imagens e momentos especiais de presença. Uma peça que esquecemos assim que saímos do teatro tem pouca ressonância. Ressonância é física, mental e uma massagem emocional acionada pelo encontro.

Voltei ao livro O Espaço Vazio, de Peter Brook, uma obra de referência que começa com a proposição de que, para se fazer teatro, necessitamos de uma pessoa que atravesse o espaço enquanto outra pessoa assiste. Eu adicionaria a questão: "Qual é a ressonância que resulta deste encontro?"

Para um ator, o ingrediente fundamental do teatro é a ação. Uma pessoa atravessa o espaço, enquanto outra pessoa assiste. No entanto, esta ação nunca é isolada e implica um engajamento compartilhado não apenas entre os atores, mas sobretudo com o público. Teatro significa avançar em grupo e não isoladamente, e as ressonâncias que vêm à tona se desenvolvem a partir da ação feita nesta unidade. Cada um de nós tem uma função e nos juntamos para fazer 
com que algo aconteça. Compartilhamos mútuas responsabilidades pela qualidade do tempo que passamos juntos. Sou responsável pela pessoa que está próxima a mim. E, desta forma, o teatro se torna um laboratório de relações. Como estamos nos relacionando? Como estamos ressoando uns com os outros?

Tal como temos visto recentemente, estarmos juntos pode ser arriscado. Antes da Covid-19, eu costumava me referir ao teatro como "respirar o mesmo ar". Porém, durante a pandemia, dividir o mesmo espaço com outras pessoas e "respirar o mesmo ar" se tornou perigoso. Conforme a pandemia avançava, me surpreendi com a ideia de um teatro feito em tendas. A metáfora de uma tenda também se tornava muito frutífera considerando os princípios da ressonância. Imagine que para cada produção seja construída uma tenda metafórica, um recinto para a jornada da peça. Para construir a tenda, o primeiro passo é fincar as vigas no solo para suporte estrutural. Estas vigas se tornam os princípios básicos, os sentidos e valores nos quais a produção teatral está alicerçada. No ensaio, por exemplo, estes eixos de sustentação se tornam o principal sistema de suporte para o projeto. O mesmo se aplica em outros processos artísticos, onde cada sustentáculo constitui um princípio para o sistema geral.

O livro tem dez capítulos, um prefácio e um posfácio. Imaginei que poderia examinar, em cada uma destas partes, as diferentes estruturas de sustentação, ou princípios, que são necessários para criar as condições para a ressonância. Os títulos dos capítulos são: Em Ressonância, Use o que Você já Tem, Sensação e Percepção, Tríade Poderosa, A Presença do Passado, Dissonância, Ambiguidade e Paradoxo, Energia e Contenção, Momento Presente, e Civilidade. ${ }^{20}$ Além de um mergulho profundo nos usos práticos da ressonância, os capítulos abordam como começar uma carreira, como alcançar as camadas de percepção mais profundas do público, como incorporar o passado no momento presente e como aceitar a dissonância, ambiguidade e paradoxo. No livro também examino o papel da energia, os usos práticos da contenção, o poder do momento presente e a necessidade de civilidade. 
Em vez de começar pela teoria, achei útil descrever meus primeiros encontros com certos conceitos, percepções e ideias. Com este espírito, The Art of Resonance está repleto de histórias da minha própria vida, aventuras e desventuras no teatro. Os frutos teóricos desses encontros e as pesquisas férteis e instigantes a que tais descobertas me levaram são o resultado de experiências de ensaio e da vida. No livro ainda trago detalhes do processo de trabalho no contexto de um grupo, especificamente a SITI Company ${ }^{21}$. Como desenvolvemos estruturas de equidade, escuta e reorientação constante. Como olhamos para as questões juntos e as debatemos abertamente ao invés de problematizá-las. Como abordamos o teatro como um lugar onde o idealismo tem vez.

Espero que The Art of Resonance seja útil ao fornecer sugestões práticas e teóricas sobre como negociar neste estado de coisas e reexaminar nossos valores, nossos métodos e instituições. Podemos questionar nossas premissas sobre como colaboramos? Temos imaginação para conceber outras maneiras de estar no mundo? Podemos nos envolver em conversas mais profundas e inclusivas com uma ampla gama de referências? Podemos criar um espaço compartilhado de mútua atenção e escuta? Como criar experiências teatrais em que a ressonância possa surgir?

Recebido em: 30/08/2021

Aprovado em: 19/09/2021

\footnotetext{
Universidade do Estado de Santa Catarina - UDESC Programa de Pós-Graduação em Teatro - PPGT Centro de Arte - CEART Urdimento - Revista de Estudos em Artes Cênicas Urdimento.ceart@udesc.br
}

\footnotetext{
21 SITI Company é a companhia teatral da qual Anne Bogart faz parte, sendo uma das diretoras e fundadoras. Criada em parceria com o diretor teatral japonês Tadashi Suzuki em 1992, a companhia tem sede na cidade de Nova York. Além de produzir espetáculos teatrais, a SITI Company desenvolve um relevante trabalho formativo, com destaque para as práticas imersivas realizadas anualmente no campus do Skidmore College, localizado na cidade de Saratoga Springs, interior do estado de Nova York. Por este motivo, o nome da companhia inclui a sigla SITI - Saratoga International Theater Institute. (NT)
} 